\title{
Isolation and in vitro antiamoebic activity of iridoids isolated from Kigelia pinnata
}

\author{
Neelam Bharti*,1,2, Shailendra Singh ${ }^{1,2}$, Fehmida Naqvi, ${ }^{2}$ and Amir Azam ${ }^{2}$ \\ ${ }^{1}$ Present address: Department of Medicinal Chemistry, College of Pharmacy, University of \\ Florida, Gainesville, FL-32610, U.S.A. \\ ${ }^{2}$ Department of Chemistry, Jamia Millia Islamia, New Delhi-110025, INDIA \\ E-mail: neelambh@ufl.edu
}

\begin{abstract}
Serial dilutions of extracts from the stem bark of Kigelia pinnata were tested for their growth inhibitory effects against Entamoeba histolytica. Butanol extract from Kigelia pinnata stem barks exhibited in vitro antiamoebic activity. Three known iridoids specioside, verminoside and minecoside were isolated, purified and identified by comparing their spectral data with the literature values. These compounds were tested against HK-9 strain of Entamoeba histolytica for their in vitro antiamoebic evaluation and metronidazole was used as reference drug in all the biological experiments. It is found that verminoside has two fold antiamoebic activity as compared to the standard drug while specioside showed comparable activity with metronidazole.
\end{abstract}

Keywords: Natural product, Kigelia pinnata, iridoids, antiamoebic activity, Entamoeba histolytica

\section{Introduction}

Amoebiasis is an ubiquitous disease and fifty million cases of amoebic dysentery and liver abscess are reported each year around the world. ${ }^{1}$ It is responsible for 100,000 deaths per year worldwide and is the second leading cause of death due to parasitic disease. ${ }^{2}$ Nitroimidazole drugs such as metronidazole [1-(2-hydroxyethyl)-2-methyl-5-nitroimidazole] are presently the most effective antiamoebic medications (Figure 1). The drug is known to have common side effects; ${ }^{3}$ It is mutagenic in bacteria and high doses in rodents can cause carcinoma. ${ }^{4}$ As a result of this and also taking into account the possibility of the development of resistant strains of the Entamoeba against metronidazole, a search for new effective amoebicidal agents is required in order to provide a new dimension in the therapy of amoebiasis. Medicinal plants are considered as an important source of potentially useful structures for the development of new chemotherapeutic agents. The first step towards this goal is the biological and phytochemical 
screening of plants extracts from traditional preparations used in popular medicine. Numerous plants are used in the indigenous system of medicine of many countries for the treatment of dysentery. ${ }^{5-11}$ They require more thorough investigation in order to validate their activity and that may uncover new leads for amoebicidal drugs.

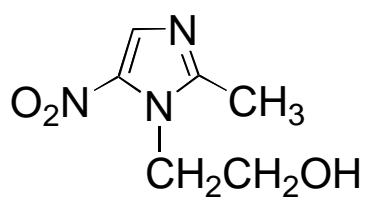

Figure 1. Metronidazole [1-(2-hydroxyethyl)-2-methyl-5-nitroimidazole].

Kigelia pinnata (K. pinnata) is an African tree which is widely grown in tropics. All parts of the tree are used for a variety of purposes in all the regions where it grows. ${ }^{12}$ Its leaves and bark was used for treating diarrhea and dysentery. ${ }^{13}$ The fruits are used as dressing for ulcers, purgative and to increase the flow of milk in lactating women. ${ }^{14}$ Different fractions of the stem bark and fruits of $K$. pinnata had shown growth inhibitory effect on four melanoma cell lines and found potential antineoplastic agent. ${ }^{15}$ The methanolic extract of the plant was found to be a potent antibacterial and antifungal agent. ${ }^{16}$ In West Africa, the root is used as a vermifuge and as a treatment for haemorrhoids and rheumatism. ${ }^{17}$ Steriods, iridiods and coumarins have been isolated from the root bark $^{18}$ and flavonoids and iridoids from the fruit and leaves. ${ }^{19}$ Dichloromethane extracts from the root and stem bark of $K$. pinnata containg naphthoquinones ${ }^{20}$

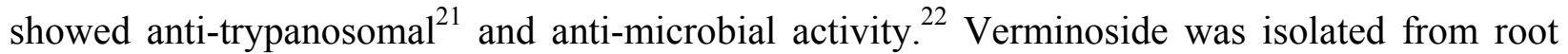
bark and showed promising anti-inflammatory activity. ${ }^{23}$ Govindachari and his colleages isolated kiglin and 6-methoxymellein together with two known compounds, stigmasterol and lapachol from the roots of this plant. ${ }^{24}$ They also isolated kigelin, $\beta$-sitosterol, 3-dimethylkigelin and ferulic acid from its bark. ${ }^{25}$ Dorothy et al. isolated five minor constituents from root bark of $K$. pinnata, which consisted of two known napthaquinones and three new aromatic monoterpenes. ${ }^{26}$ Two non-quinonoid aldehydes, norviburtinal and pinnatal were obtained from the root bark by Joshi et al. ${ }^{27}$ Literature survey showed that no antiamoebic screening has been reported on this plant.

The present paper reports isolation and in vitro antiamoebic activity of three iridoids as well as extracts from stem bark of $K$. pinnata. Biologically monitored fractionation of the butanol extract from stem bark of $K$. pinnata led us to the isolation of three known iridoids; specioside, verminoside and minecoside. Specioside, verminoside and minecoside were isolated earlier from root bark of $K$. pinnata ${ }^{18}$ and further characterized by El- Naggar et $\mathrm{al}^{28}$ and Sticher et $\mathrm{al}^{29}$ All the compounds were identified by comparing their UV, IR and ${ }^{1} \mathrm{H}$ NMR data with the literature values. ${ }^{18,28,29}$ In vitro antiamoebic activity of extracts and isolated compounds were carried out against HK-9 strain of E. histolytica by using micro dilution method. 


\section{Results and Discussion}

Powered dried stem bark was defatted with hexane and exhaustively extracted from cold methanol. The extract was concentrated under vacuum and the residue was dissolved in water. The aqueous layer was extracted with butanol and ethyl acetate successively. The butanol extract was digested with chloroform and the residue was subjected to column chromatography which leads to the isolation of three major constituents. Three known iridoids, specioside (I), verminoside (II) and minecoside (III) (Figure 2) were isolated from biological monitored fractionation of the butanol extract. The structures of these compounds I, II and III were confirmed by comparing their spectroscopic data (UV, IR and ${ }^{1} \mathrm{H}$ NMR) with the literature values. $^{18,28,29}$

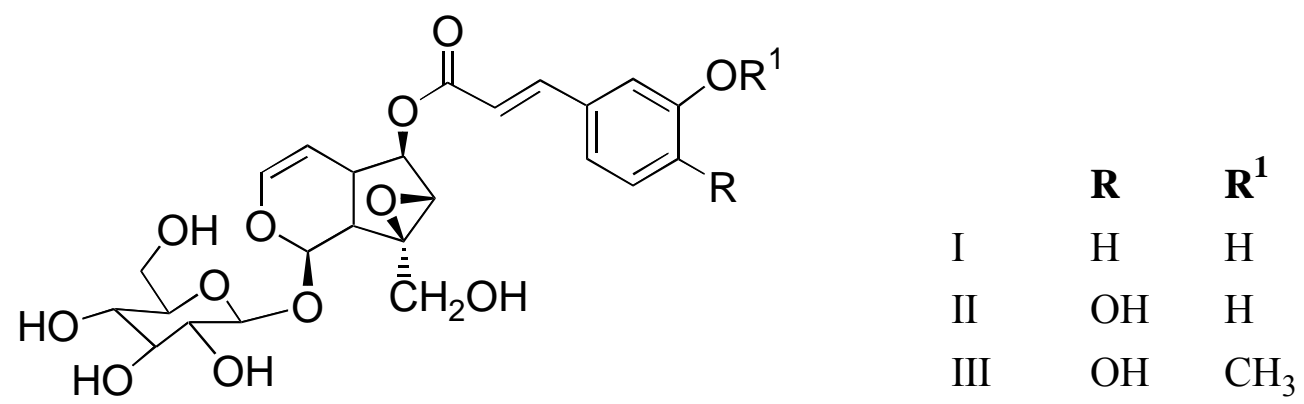

Figure 2. Structure of specioside (I), verminoside (II) and minecoside (III).

Axenic culture of HK-9 strains of E. histolytica was maintained in diamond's TYIS-33 medium. ${ }^{30}$ Heat inactivated bovine serum was used to give a more favorable growth. Metronidazole was used as the reference drug in all the biological experiments. All the plant extracts and compounds including metronidazole were dissolved in dimethylsulfoxide (DMSO). The maximum concentration of DMSO in the test did not exceed $0.1 \%$ at which level no inhibition of amoebal growth occurred. ${ }^{31,32} \mathrm{IC}_{50}$ (50\% inhibition concentration) values of plant extracts and the isolated compound have been determined by using the microdilution method. ${ }^{33}$ The antiamoebic effect was compared with the most widely used antiamoebic medication metronidazole. The percentage inhibition values obtained was transformed into probit values and regression analysis was undertaken in order to find the best fitting straight line through the point obtained. At least three experiments were performed for each compound or plant extract tested. The in vitro antiamoebic screening of fractions of plant extract and compound isolated against HK-9 strain of E. histolytica are summarized in Table 1 and 2. The Metronidazole had a 50\% inhibitory concentration $\left(\mathrm{IC}_{50}\right)$ of $0.33 \mathrm{mg} / \mathrm{mL}$ in our experiment which is close to the previously reported $\mathrm{IC}_{50}$ of $0.32 \mathrm{mg} / \mathrm{mL}$ obtained against $E$. histolytica. ${ }^{34}$ When all the fractions of plant extract are tested against E. histolytica it is found that the butanol fractions of $K$. pinnata possessed good antiamoebic activity. The major iridoids constituents were present in the butanol extract of K. pinnata. These iridoids were highly active against amoeba and account for the high 
potency of the butanol extract. Verminoside was found highly active $\left(\mathrm{IC}_{50} 0.19 \mu \mathrm{g} / \mathrm{mL}\right.$ as compared to metronidazole $\mathrm{IC}_{50} 0.33 \mu \mathrm{g} / \mathrm{mL}$ ) than the standard drug while specioside $\left(\mathrm{IC}_{50} 0.39\right.$ $\mu \mathrm{g} / \mathrm{mL}$ ) was as active as metronidazole.

Table 1. In vitro antiamoebic activity of crude extracts from Kigelia pinnata stem bark against E. histolytica

\begin{tabular}{lll}
\hline Fraction & $\mathrm{IC}_{50}(\mu \mathrm{g} / \mathrm{mL})$ & S.D. \\
\hline Hexane & 213.04 & 23.28 \\
Chloroform & 18.03 & 1.22 \\
Ethyl acetate & 61.60 & 13.69 \\
Butanol & 1.36 & 0.35 \\
Metronidazole & 0.33 & 0.08 \\
\hline
\end{tabular}

Table 2. In vitro antiamoebic activity of isolated iridoids from Kigelia pinnata against E. histolytica

\begin{tabular}{llll}
\hline & Compound & $\mathrm{IC}_{50}(\mu \mathrm{g} / \mathrm{mL})$ & S.D. \\
\hline I & Specioside & 0.39 & 0.08 \\
II & Verminoside & 0.19 & 0.04 \\
III & Minecoside & 0.74 & 0.17 \\
& Metronidazole & 0.33 & 0.08 \\
\hline
\end{tabular}

\section{Conclusions}

The natural products have potential in the search for new and selective agents for the treatment of important tropical diseases caused by protozoa. In this study, K. pinnata was studied for its antiamoebic evaluation which is being used in traditional systems of medicine against dysentery and diarrhea. Three known iridoids specioside, verminoside and minecoside were isolated and screened in vitro against HK-9 strain of E. histolytica. Verminoside was found to be more active than the standard drug while specioside showed activity comparable to metronidazole. It is hoped that these studies will stimulate further efforts towards the development of new and urgently needed medications for the treatment of amoebiasis.

\section{Experimental Section}

General Procedures. UV/Vis spectra were recorded in methanol on a Shimadzu UV-1601 PC UV/Visible spectrophotometer, IR spectra in $\mathrm{KBr}$ on a Perkin-Elmer model 1620 FT-IR spectrometer and ${ }^{1} \mathrm{H}$ NMR spectra on Bruker spectrospin DPX-300 MHz in $\mathrm{CD}_{3} \mathrm{OD}$. Column 
fractions were analysed by thin layer chromatography on precoated aluminium sheets gel TLC $60 \mathrm{~F}_{254}$ (Merck) by using the following solvents ratios; (a) acetone-methanol (9:1), (b) chloroform-ethyl acetate (5:2), (c) chloroform-methanol (5:1), (d) chloroform-methanol-water (65:20:15, lower phase) and zones were detected by examination in UV light 254 and $365 \mathrm{~nm}$ and after spraying with $0.5 \%$ anisaldehyde in sulphuric acid-AcOH-methanol $(1: 2: 17)$ and heating at $105^{\circ} \mathrm{C}$ for $10 \mathrm{~min}$.

Plant material. The stem barks of Kigelia pinnata were collected from New Delhi, India. The plant was identified by a botanist at the Department of Botany, Chaudhary Charan Singh University, INDIA and specimens are deposited in the herbarium of the Chaudhary Charan Singh University.

Extraction and Isolation of Iridoids (I-III) from K. pinnata. The plant sample was cut into small pieces and air-dried in the shade for several days. A $2 \mathrm{~kg}$ air dried stem bark was defatted with hexane and percolated with methanol at room temperature and then extracted exhaustively with cold methanol. The methanol extract was concentrated under reduced pressure to yield 300 $\mathrm{g}$ residue. The residue was dissolved in $500 \mathrm{~mL}$ water and the aqueous layer was extracted with 6 x $100 \mathrm{~mL}$ 2-butanol and ethyl acetate. The extracts were concentrated under vacuo to yield $6.63 \mathrm{~g}$ and $4.80 \mathrm{~g}$, respectively. The butanol fractions residue was digested with chloroform, filtered and subjected to column chromatography. It was eluted with dichloromethane, chloroform with increasing proportion of acetone. After elution with acetone, proportions of methanol were gradually increased as the eluting solvent until methanol was used. Each elute was examined on TLC using the solvent system chloroform-methanol-water $(65: 20: 15)$ and fractions with the similar Rf values were combined. Many minor components were detected in elutes of chloroform-acetone. Large amounts of another three compounds were detected in acetonemethanol (9:1) elutes and these have been shown to be iridoids (I-III). ${ }^{18,28,29}$

Specioside (I). Colorless microcrystals; Yield-50 mg; $\left(\mathrm{C}_{24} \mathrm{H}_{28} \mathrm{O}_{12}\right)$; UV, IR and ${ }^{1} \mathrm{H}$ NMR were consistent with those previously reported. ${ }^{28}$

Verminoside (II). Pale yellow amorphous powder, Yield-65 mg; $\left(\mathrm{C}_{24} \mathrm{H}_{28} \mathrm{O}_{13}\right)$; UV, IR and ${ }^{1} \mathrm{H}$ NMR were consistent with those previously reported. ${ }^{29}$

Minecoside (III). White powder, Yield-35 mg; $\left(\mathrm{C}_{25} \mathrm{H}_{30} \mathrm{O}_{13}\right)$; UV, IR and ${ }^{1} \mathrm{H}$ NMR were consistent with those previously reported. ${ }^{29}$

In vitro testing against $\boldsymbol{E}$. histolytica. Activity against E. histolytica (strain HK-9) in vitro was assessed using a microtiter plate method. ${ }^{33}$ DMSO $(40 \mu \mathrm{L})^{31,32}$ was added to sample of plant extracts $(\sim 10 \mathrm{mg})$ or compounds $(\sim 1 \mathrm{mg})$ followed by enough culture medium to obtain concentrations of 10 or $1 \mathrm{mg} / \mathrm{mL}$. Samples were dissolved by mild sonication in a sonicator bath for a few minutes and then further diluted with medium to concentrations of 1.0 or $0.1 \mathrm{mg} / \mathrm{mL}$. Two-fold serial dilutions were made in the wells of 96-well microtiter plate (Nunc) in $170 \mu \mathrm{L}$ of medium. Each test included metronidazole as a standard amoebicidal drug, control wells (culture medium plus amoebae) was prepared from a confluent culture by pouring off the medium, adding $2 \mathrm{~mL}$ of medium and chilling the culture on ice to detach the organisms from the side of the flask. The number of amoeba per $\mathrm{mL}$ was estimated with a haemocytometer and trypan blue 
exclusion was used to confirm viability. Fresh culture medium was added to dilute the suspension to $10^{5}$ organism $/ \mathrm{mL}$, and $170 \mu \mathrm{L}$ of this suspension was added to the test and control wells in the plate so that the wells were completely filled (total volume, $340 \mu \mathrm{L}$ ). An inoculum of $1.7 \times 10^{4}$ organisms/well was chosen so that confluent, but not excessive growth took place in the control wells. The plate was sealed with expanded polystyrene. Secured with tape, placed in a modular incubating chamber (flow laboratories, High Wycombe, UK), and gassed for $10 \mathrm{~min}$ with nitrogen before incubation at $37^{\circ} \mathrm{C}$ for $72 \mathrm{~h}$.

Assessment of antiamoebic activity. After incubation, the growth of amoebae in the plate was checked with a low power microscope. The culture medium was removed by inverting the plate and shaking gently. The plate was then immediately washed once in sodium chloride solution $(0.9 \%)$ at $37^{\circ} \mathrm{C}$. This procedure was completed quickly, and the plate was not allowed to cool in order to prevent the detachment of amoebae. The plate was allowed to dry at room temperature, and the amoebae were fixed with methanol, when dry, stained with $(0.5 \%)$ aqueous eosin for 15 min. The stained plate was washed once with tap water and then twice with distilled water and allowed to dry. A $200 \mu \mathrm{L}$ portion of $0.1 \mathrm{~N}$ sodium hydroxide solution was added to each well to dissolve the protein and release the dye. The optical density of the resulting solution in each well was determined at $490 \mathrm{~nm}$ with a microplate reader (Labsystem Multiskane Bichromatic, UK). The $\%$ inhibition of amoebal growth was calculated from the optical densities of the control and test wells and plotted against the logarithm of the dose of the drug tested. Linear regression analysis was used to determine the best-fitting straight line from which the $\mathrm{IC}_{50}$ value was determined.

\section{Acknowledgements}

We thank the Central Council of Research in Unani Medicine, Ministry of Health, New Delhi, INDIA for financial support. Prof. Alok Bhattacharya and Dr. Sudha Bhattacharya, School of Life Sciences and School of Environmental Sciences, Jawaharlal Nehru University, New Delhi, respectively are gratefully acknowledged for biological activity test facilities. Many thanks to Dr. Prabhu P. Mohapatra, Department of Chemistry, University of Florida, Gainesville, USA for valuable discussions and important suggestions.

\section{References and Footnotes}

1. Walsh, J. A. Rev. Infect. Dis. 1986, 8, 2228.

2. WHO. Report of the expert consultation on amoebiasis, WHO. Epidemiol. Record 1997, 14, 4.

3. Martinez, P. A. Biology of Entamoeba histolytica In: Amoebiasis P. A. Martinez, P. A., Ed., Elsevier: Amsterdam, 1986, pp 12-43. 
4. Voogd, C. E.; Van der Stel, J. J.; Jacobs, J. J. A. A. Mutat. Res. 1974, 26, 483.

5. Steck, E. A. The Chemotherapy of Protozoan Disease, Vol. 1, Walter Reed Army Institute: U.S. Government Printing, Washington, 1972.

6. Neal, R. A. Parasitol. 1983, 86, 175.

7. Chopra, R. N.; Nayar, S. L.; Chopra, I. C. Glossary of Indian Medicinal Plants, Council of Scitific and Industrial Research: New Delhi, 1956.

8. Anon, Barefoot Doctors Manual of the Revolutionary Committee of Yunan Province, Routledge and Kegan Paul: London, 1978.

9. Ayensu, E. S. Medicinal Plants of the West Indies, Reference Publication, U.S.A. 1981.

10. Diaz, J. L. Usos de las Plantas medicinale de Mexico, Vol. 2, Instituto Mexicano papa el studio de las plantas medicinales AC, Mexico, 1976.

11. Leung, A. Y. Encyclopedia of common natural ingredients used in food, drugs and cosmetics, J. Wiley: New York, 1980.

12. Heine, H. In Flora of Tropical West Africa by Hutchinson, J. and Dalziel, J. M. $2^{\text {nd }}$ Edn. Hepper, N. Ed., Vol. II, 1963, pp 385.

13. Burkill, H. M. The useful plants of Tropical West Africa, Vol. I Families A-D, Royal Botanical Garden, Kew 1985, pp 254.

14. Oliver-Bever, B. Medicinal Plants in Tropical West Africa, Cambridge University Press: Cambridge, London, New York, New Rochelle, Melbourne, Sydney. 1986, pp 240.

15. Jackson, S. J.; Haughton, P. J.; Retsas, S.; Photiou, A. Planta Med. 2000, 66, 758.

16. Oluwatoyin, A.; Kayode, E.; Joseph, A.; Okogun, I. Planta Med. 1996, 62, 352.

17. Irvine, F. R. Woody Plants of Ghana. Oxford University Press: Oxford, 1961, pp 736.

18. Houghton, P. J.; Akuniyli, D. N. Fitoterapia 1993, 65, 473.

19. Gouda, Y. G.; Abdel-Baky, A. M.; Darwish, F. M.; Mohamed, K. M.; Kasal, R.; Yamasaky, K. Phytochemistry 2003, 63, 887.

20. Jackson, S. J.; Houghton, P. J.; Retsas, S.; Photiou, A. Planta Med. 2000, 66, 758.

21. Moideen, S. V. K.; Houghton, P. J.; Rock, P.; Croft, S. L:, Aboagye-Nyame, F. Planta Med. 1999, 65, 536.

22. Akunyili, D. N.; Houghton, P. J.; Roman, A. J. Ethnopharm. 1991, 35, 173.

23. Picerno, P.; Autore, G.; Marzocco, S.; Meloni, M.; Sanogo, R.; aquino, R. P. J. Nat. Prod. 2005, 68, 1610.

24. Govindachari, T. R.; Patankar, S. J.; Vishvanathan, N. Phytochemistry 1971, 10, 1603.

25. Desai, H. K.; Gawad, D. H.; Govindachari, T. R.; Joshi, B. S.; Kamat, V. N.; Modi, J. D.; Parthasarathy, P. C.; Patanker, S. J.; Sidhye, A. R.; Viswanathan, N. Ind. J. Chem. 1971, 9, 611.

26. Akunyili, D. N.; Houghton, P. J. Phytochemistry 1993, 32, 1015.

27. Joshi, K. C.; Singh, P.; Taneja, S.; Cox, P. J.; Howie, R. A. Phytochemistry 1982, 21, 2703.

28. El- Naggar, S.F.; Doskotch, R. W. J. Nat. Prod. 1980, 43, 524.

29. Sticher, V. O.; Afifi-Yazar, F. U. Helv. Chim. Acta 1979, 62, 535. 
30. Diamond, L. S; Harlow, D. R.; Cunnick, C. C. Trans. R. Soc. Trop. Med. Hyg. 1978, 72, 431.

31. Gillin, F. D.; Reiner,M. Suffness, D.S. Antimicrob. Agents Chemother. 1982, 22, 342.

32. Keen, A.T.; Harris, A.; Phillipson, J. D.; Warhurst, D. C. Planta Med. 1986, 278.

33. Wright, C. W.; O'Neill, M. J.; Phillipson, J. D.; Warhurst, D. C. Antimicrob. Agents Chemother. 1988, 1725.

34. Wright, C. W.; O'Neill, M. J.; Phillipson, J. D.; Warhurst, D. C. J. Pharm. Pharmacol. 1987, 39, 105. 